Supporting Information

\title{
A Device Architecture Study in Fullerene-Based Organic Photovoltaics
}

Lakshmi N. S. Murthy', Boya Zhang†, Julia W. P. Hsü *

${ }^{\dagger}$ Department of Materials Science and Engineering, University of Texas at Dallas, Richardson, TX, 75080 USA

Corresponding Author

*E-mail: jwhsu@utdallas.edu

Supporting Information Details:

Number of pages : 12

Number of figures : 6

Number of tables : 1 


\section{Table of contents}

\section{FIGURES}

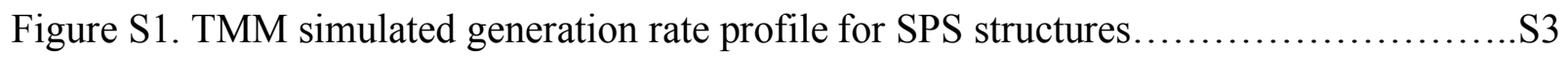

Figure S2. TMM simulated generation rate profile for complete device structures.............S4

Figure S3. Electric field intensity distribution for different wavelengths..................S5

Figure S4. SCAPS simulated recombination rate profile.............................. 6

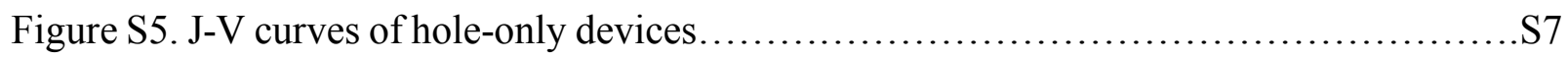

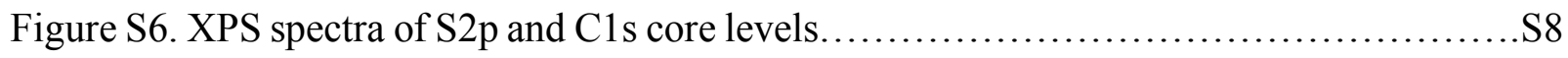

\section{TABLES}

Table S1. Materials parameters for drift-diffusion simulation.........................S6 


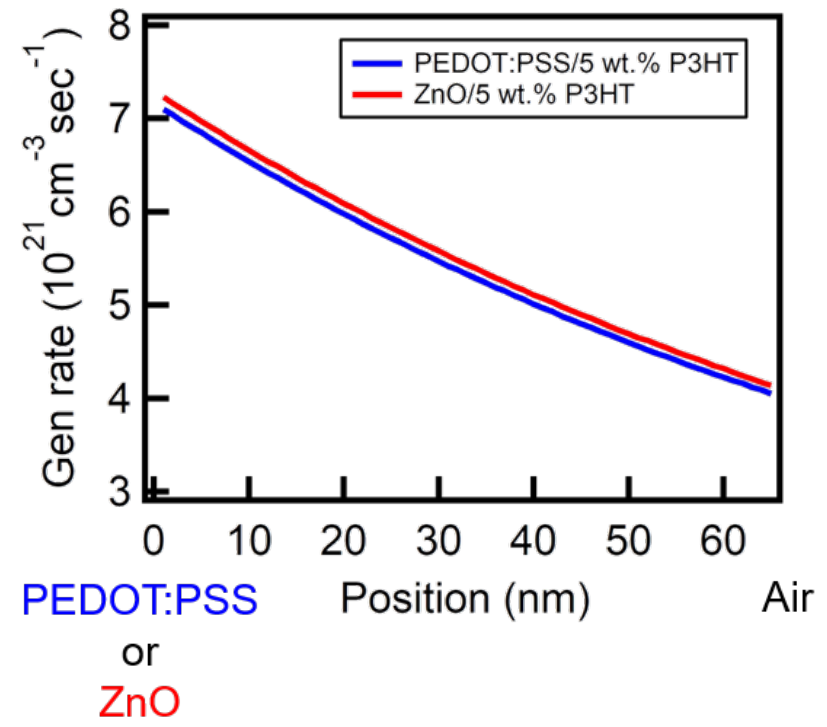

Figure S1. TMM simulated generation rate as a function of position in a $65 \mathrm{~nm} 5 \mathrm{wt}$ \% P3HT layer on top of PEDOT:PSS (blue) and $\mathrm{ZnO}$ (red). Position $0 \mathrm{~nm}$ refers to PEDOT:PSS/5 wt.\% P3HT interface for the conventional and $\mathrm{ZnO} / 5 \mathrm{wt} . \% \mathrm{P} 3 \mathrm{HT}$ interface for the inverted structure.

Position $65 \mathrm{~nm}$ refers to $5 \mathrm{wt}$ \% P3HT/air interface for both conventional and inverted structures. 

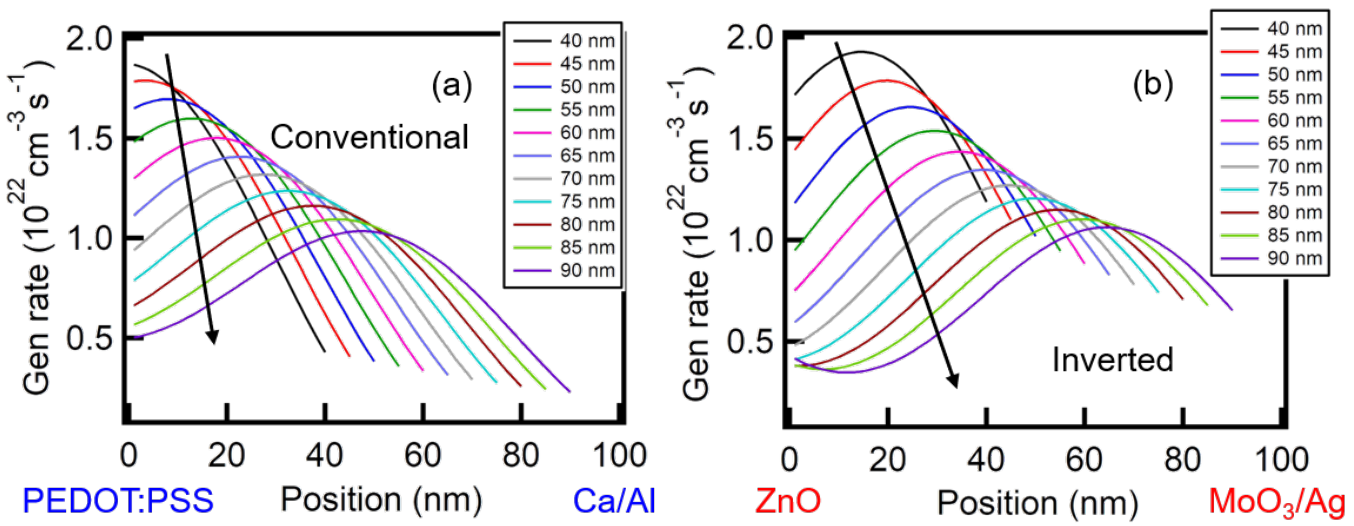

Figure S2. TMM simulated generation rate profile (solid line) as a function of position of $5 \mathrm{wt} . \%$ P3HT layer with different thickness : $40 \mathrm{~nm}$ (black), $45 \mathrm{~nm}$ (red), $50 \mathrm{~nm}$ (blue), $55 \mathrm{~nm}$ (green), $60 \mathrm{~nm}$ (pink), $65 \mathrm{~nm}$ (neon blue), $70 \mathrm{~nm}$ (grey), $75 \mathrm{~nm}$ (light blue), $80 \mathrm{~nm}$ (brown), $85 \mathrm{~nm}$ (bright green), and $90 \mathrm{~nm}$ (violet) in (a) conventional and (b) inverted devices. Position $0 \mathrm{~nm}$ refers to PEDOT:PSS/5wt.\% P3HT interface for the conventional and $\mathrm{ZnO} / 5$ wt.\% P3HT interface for the inverted structure. The arrows in (a) and (b) indicate increasing active layer thickness. 

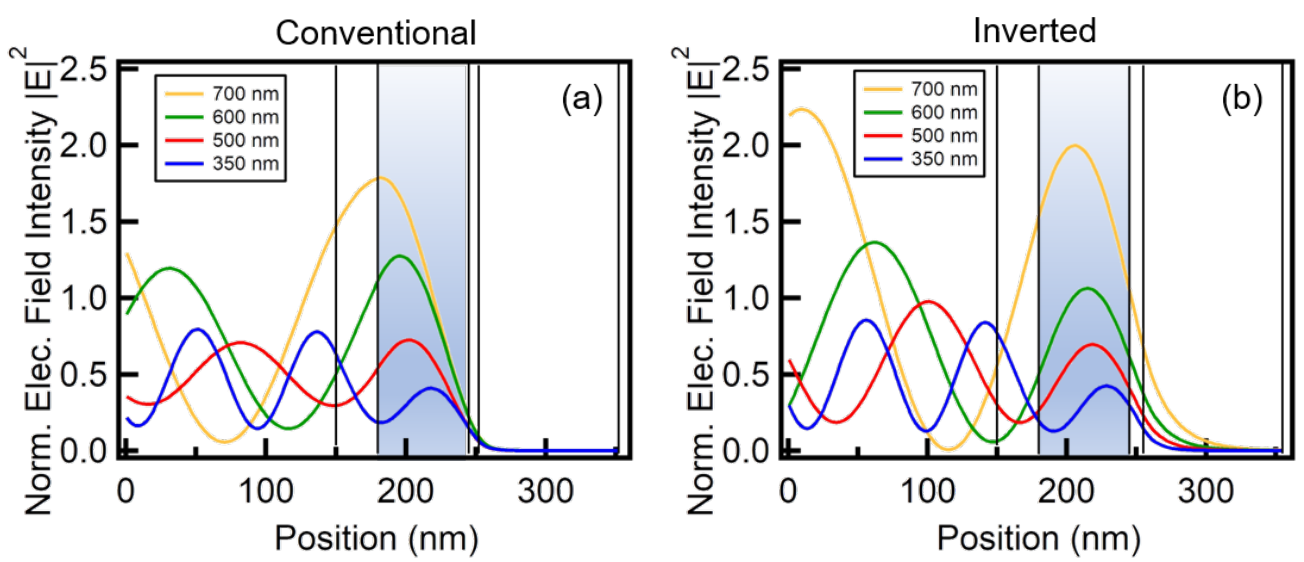

Figure S3. Electric field intensity (normalized to incident light intensity) distribution for wavelengths: $700 \mathrm{~nm}$ (yellow), $600 \mathrm{~nm}$ (green), $500 \mathrm{~nm}$ (red), and $350 \mathrm{~nm}$ (blue). (a) Conventional architecture: ITO (150 nm)/PEDOT:PSS (30 nm)/5 wt.\% P3HT (65 nm)/Ca (7 $\mathrm{nm}) / \mathrm{Al}(100 \mathrm{~nm})$, and (b) inverted architecture: ITO (150 nm)/ZnO (30 nm)/5 wt.\% P3HT (65 $\mathrm{nm}) / \mathrm{MoO}_{3}(10 \mathrm{~nm}) / \mathrm{Ag}(100 \mathrm{~nm})$ devices. The blue shaded regions in (a) and (b) represent the active layer (5 wt.\% P3HT). 

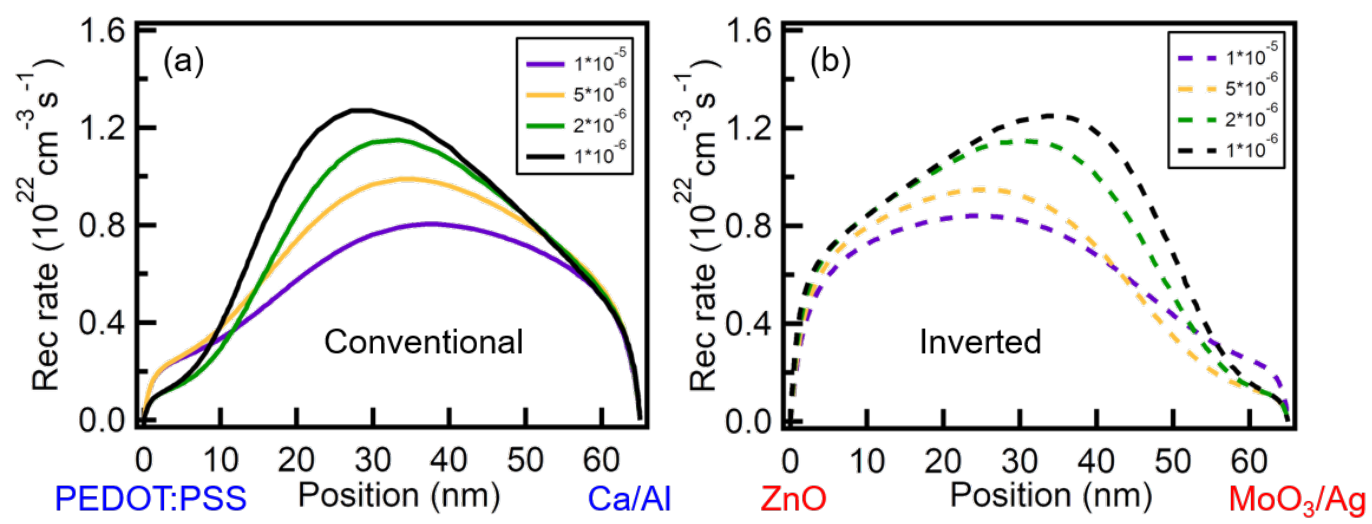

Figure S4. SCAPS simulated recombination rate as a function of $65 \mathrm{~nm} 5 \mathrm{wt} . \% \mathrm{P} 3 \mathrm{HT}$ layer position with varying hole mobilities : $1 \times 10^{-5} \mathrm{~cm}^{2} \mathrm{~V}^{-1} \mathrm{~s}^{-1}$ (purple), $5 \times 10^{-6} \mathrm{~cm}^{2} \mathrm{~V}^{-1} \mathrm{~s}^{-1}$ (yellow), $2 \times 10^{-6} \mathrm{~cm}^{2} \mathrm{~V}^{-1} \mathrm{~s}^{-1}$ (green), $1 \times 10^{-6} \mathrm{~cm}^{2} \mathrm{~V}^{-1} \mathrm{~s}^{-1}$ (black) in (a) conventional (solid lines) and (b) inverted (dashed lines) devices. Position $0 \mathrm{~nm}$ and $65 \mathrm{~nm}$ refers to front and rear electrode of the devices, respectively.

Table S1. Material parameters used for drift-diffusion simulation using SCAPS

\begin{tabular}{cc} 
Parameters & Values \\
Electron affinity $(\mathrm{eV})$ & 3.7 \\
CB and VB effective density of states $\left(\mathrm{cm}^{-3}\right)$ & $1 * 10^{20}$ \\
Anode work function $(\mathrm{eV})$ & 5.1 \\
Cathode work function $(\mathrm{eV})$ & 4 \\
Bimolecular recombination coefficient $\left(\mathrm{cm}^{3} \mathrm{~s}^{-1}\right)$ & $1 * 10^{-12}$ \\
Effective bandgap $(\mathrm{eV})$ & 1.45 \\
Electron mobility $\left(\mathrm{cm}^{2} \mathrm{~V}^{-1} \mathrm{~s}^{-1}\right)$ & $1 * 10^{-3}$ \\
\hline
\end{tabular}




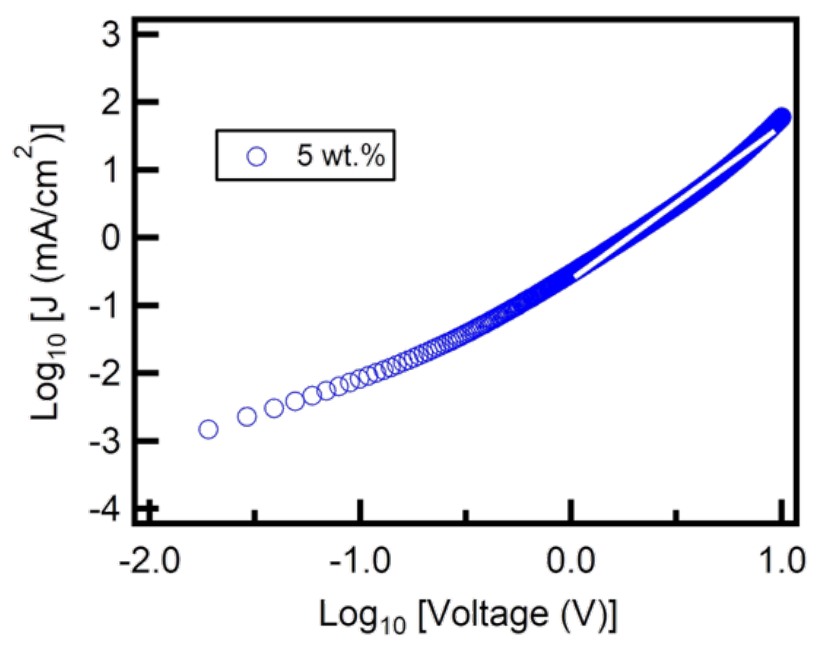

Figure S5. (a) J-V curves (in log scale) of hole-only devices with 5 wt.\% P3HT (open blue circles). Hole mobility is extracted using SCLC equation in the fitting range (white line).

The hole mobility is extracted using space charge limited current (SCLC) equation $J_{S C L C}=\frac{9 \varepsilon \mu_{h} V^{2}}{8 d^{3}}\left[\exp \left(0.89 \gamma \sqrt{\frac{V}{d}}\right)\right],{ }^{1}$ where $\mathrm{J}_{\mathrm{SCLC}}$ is current density, $\varepsilon$ is the dielectric constant (4.5), $\mathrm{d}$ is the active layer thickness $(65 \mathrm{~nm}), \mu_{\mathrm{h}}$ is hole mobility $\left(3.8 \times 10^{-6} \mathrm{~cm}^{2} \mathrm{~V}^{-1} \mathrm{~s}^{-1}\right)$, and $\gamma$ is a parameter that describes the field dependence effect $\left(1.2 \times 10^{-3} \mathrm{~cm}^{1 / 2} \mathrm{~V}^{-1 / 2}\right)$. 
(a) Conventional, under contact
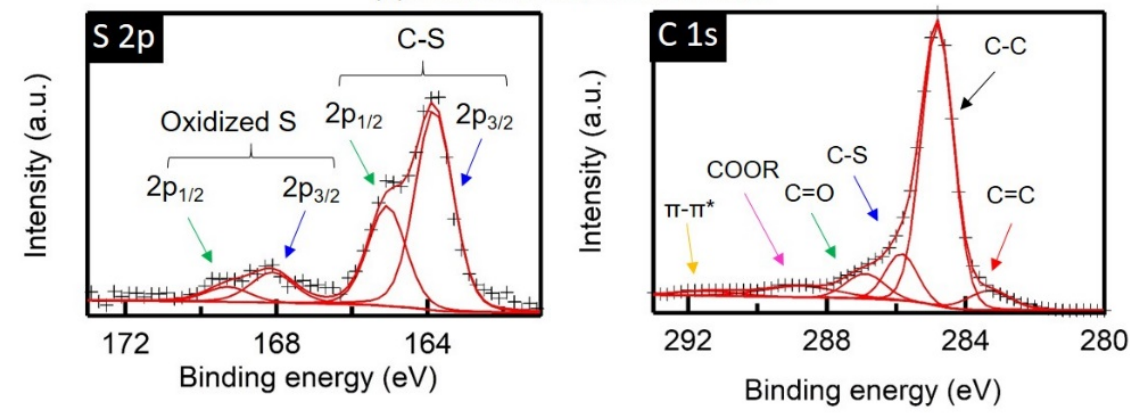

(b) Conventional, away from contact
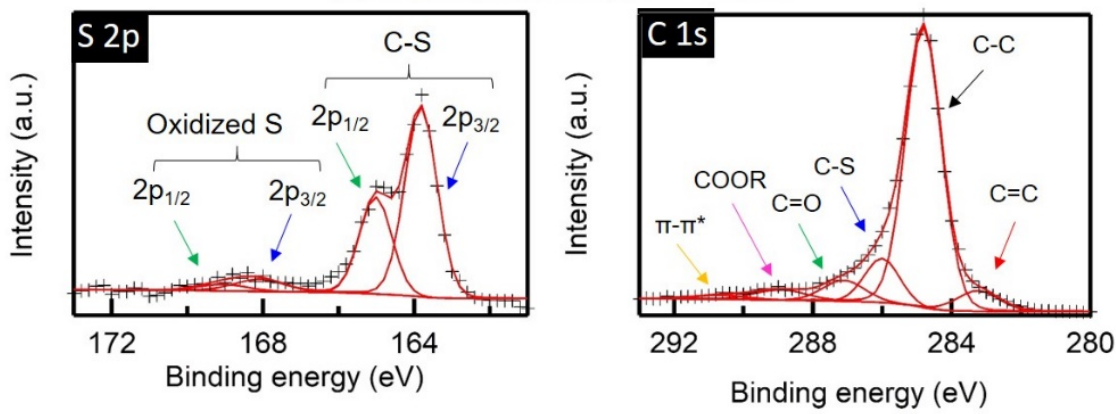

(c) Inverted, under contact
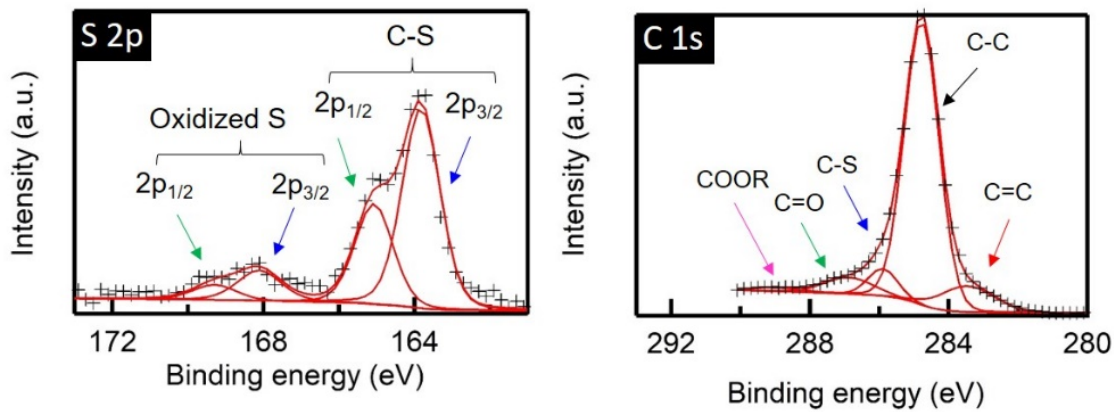

(d) Inverted, away from contact
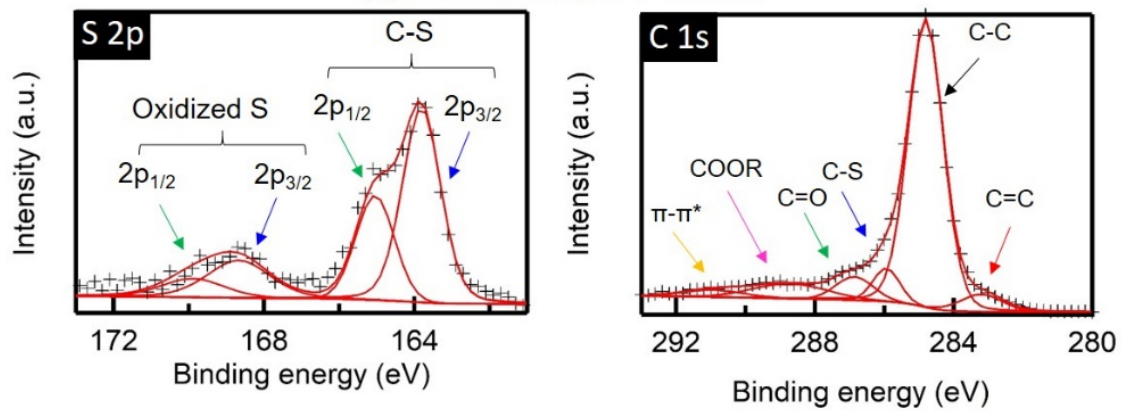

Figure S6. XPS spectra of S 2p (left) and C 1s (right) core-levels for 5 wt.\% P3HT (a) conventional devices under $\mathrm{Ca}(7 \mathrm{~nm}) / \mathrm{Al}(100 \mathrm{~nm})$ contact, (b) conventional devices away from contact, (c) inverted devices under $\mathrm{MoO}_{3}(10 \mathrm{~nm}) / \mathrm{Ag}(100 \mathrm{~nm})$ contact, and (d) inverted devices 
away from contact. The contacts are removed by Scotch tape prior to the experiment. The measured and fitted data are represented by black cross marks and red lines, respectively. In S 2p spectra, the blue and green arrows represent $\mathrm{S} 2 \mathrm{p}_{3 / 2}$ and $\mathrm{S} 2 \mathrm{p}_{1 / 2}$ signal, respectively. In $\mathrm{C} 1 \mathrm{~s}$ spectra, the red, black, blue, green, pink, and yellow arrows represent $\mathrm{C}=\mathrm{C}, \mathrm{C}-\mathrm{C}, \mathrm{C}-\mathrm{S}, \mathrm{C}=\mathrm{O}$, COOR, and $\pi-\pi^{*}$ signals.

Figure S6 shows measured (black crosses) and fitted (solid red lines) XPS spectra of C 1s and $\mathrm{S} 2 \mathrm{p}$ core-levels of $5 \mathrm{wt} . \% \mathrm{P} 3 \mathrm{HT}$ in conventional and inverted devices. Binding energies are referenced to $\mathrm{C} 1 \mathrm{~s}$ at $284.8 \mathrm{eV}$. The peak fitting was performed using a Gaussian-Lorentzian profile with a Shirley type background correction. ${ }^{2}$ In C 1s spectra, the main peaks at $\sim 284.8 \mathrm{eV}$ were fitted to $\mathrm{sp}^{3} \mathrm{C}$ corresponding to $\mathrm{C}-\mathrm{C}$ bond in the alkyl side chains from $\mathrm{P} 3 \mathrm{HT}$ or $\mathrm{PC}_{71} \mathrm{BM}$ and adventitious carbon caused by air exposure. ${ }^{3-6}$ The peaks at $\sim 283.3 \mathrm{eV}$ were fitted to $\mathrm{sp}^{2} \mathrm{C}$ corresponding to $\mathrm{C}=\mathrm{C}$ bond from $\mathrm{P} 3 \mathrm{HT}$ or $\mathrm{PC}_{71} \mathrm{BM} .{ }^{3,5,6}$ The peaks at $\sim 285.9 \mathrm{eV}$ were fitted to C-S bond in the thiophene ring of P3HT ${ }^{5-8}$ The peaks at $\sim 286.9 \mathrm{eV}$ and $\sim 288.8 \mathrm{eV}$ were fitted to $\mathrm{C}=\mathrm{O}$ and $\mathrm{COOR}$ bonds, respectively, related to oxidized $\mathrm{C}$ caused by air exposure. ${ }^{5,6,8}$ The peaks at $\sim 291.0 \mathrm{eV}$ were fitted to $\pi-\pi^{*}$ shake-up satellites related to the delocalization of $\pi$ orbitals along the polymer backbones or inside the polymeric film. ${ }^{5,8}$.

In $S 2 p$ spectra, the area ratio of peak resulting from the spin-orbit coupling was fixed to $2: 1$ for $S 2 p_{3 / 2}: 2 p_{1 / 2}$ line. The full width at half maximum for all $S$ peaks was kept constant. The $S 2 p$ spectra at lower binding energy $(\sim 162.0 \mathrm{eV}-167.0 \mathrm{eV})$ were fitted to $\mathrm{S} 2 \mathrm{p}_{3 / 2}$ and $\mathrm{S} 2 \mathrm{p}_{1 / 2}$ peaks at $\sim 163.6 \mathrm{eV}$ and $\sim 165.0 \mathrm{eV}$, respectively. These binding energies correspond to the $\mathrm{S}$ signals from C-S bond in the thiophene ring of P3HT., Similarly, the S 2p spectra at higher binding energy $(\sim 167.0 \mathrm{eV}-172.0 \mathrm{eV})$ were fitted to $\mathrm{S} 2 \mathrm{p}_{3 / 2}$ and $\mathrm{S} 2 \mathrm{p}_{1 / 2}$ peaks at $\sim 168.2 \mathrm{eV}$ and $\sim 169.4$ 
$\mathrm{eV}$, respectively, corresponding to oxidized $\mathrm{S}$ (e.g. sulfoxide and sulfone) from binding to more electronegative oxygen atom caused by air exposure. ${ }^{8,10}$

The S/C atomic ratios were calculated from areas under the fitted peaks, including both C-S and oxidized S peaks using the following equation: ${ }^{11}$

$\frac{S}{C}=\frac{A_{S} / A S F_{S}}{A_{C} / A S F_{C}}$

where $A_{S}$ and $A_{C}$ are the total peak areas of $S 2 p$ core levels and $C$ 1s core levels, respectively, and $\mathrm{ASF}_{\mathrm{S}}$ and $\mathrm{ASF}_{\mathrm{C}}$ are the corresponding atomic sensitivity factors obtained from Multipak software.

\section{REFERENCES}

(1) Blakesley, J. C.; Castro, F. A.; Kylberg, W.; Dibb, G. F.A.; Arantes, C.; Valaski, R.; Cremona, M.; Kim, J. S.; Kim, J.-S. Towards Reliable Charge-Mobility Benchmark Measurements for Organic Semiconductors. Org. Electron. 2014, 15, 1263-1272.

(2) Thampy, S.; Ibarra, V.; Lee, Y.-J.; McCool, G.; Cho, K.; Hsu, J. W.P. Effects of Synthesis Conditions on Structure and Surface Properties of $\mathrm{SmMn}_{2} \mathrm{O}_{5}$ Mullite-Type Oxide. Appl. Surf. Sci. 2016, 385, 490-497.

(3) Rafique, S.; Abdullah, S. M.; Badiei, N.; McGettrick, J.; Lai, K. T.; Roslan, N. A.; Lee, H. K. H.; Tsoi, W. C.; Li, L. An Insight Into the Air Stability of the Benchmark Polymer:Fullerene Photovoltaic Films and Devices: a Comparative Study. Org. Electron. 2020, 76, 105456. 
(4) Juarez-Perez, E. J.; Ono, L. K.; Maeda, M.; Jiang, Y.; Hawash, Z.; Qi, Y. Photodecomposition and Thermal Decomposition in Methylammonium Halide Lead Perovskites and Inferred Design Principles to Increase Photovoltaic Device Stability. J. Mater. Chem. A 2018, 6, 9604-9612.

(5) Parmeggiani, M.; Verna, A.; Ballesio, A.; Cocuzza, M.; Piatti, E.; Fra, V.; Pirri, C. F.; Marasso, S. L. P3HT Processing Study for In-Liquid EGOFET Biosensors: Effects of the Solvent and the Surface. Sensors 2019, 19, 4497.

(6) Santos, B. P. S.; Arias, J. J. R.; Albuquerque, L. S.; da Veiga, A. G.; de Melo Furtado, J. G.; de Castro Ribeiro, A.; da Silva, L. A. F.; Bendinelli, E. V.; Rocco, M. L. M.; Valaski, R.; et al. An Investigation on the Effect of the Monomer/Catalyst Ratio in the Electronic Properties of Poly(3Hexylthiophene) Using XPS, REELS and UPS Techniques. J. Electron Spectrosc. Relat. Phenom. 2019, 234, 27-33.

(7) Sharma, T.; Singhal, R.; Vishnoi, R.; Lakshmi, G. B. V. S.; Chand, S.; Avasthi, D. K.; Kanjilal, A.; Biswas, S. K. Ion Irradiation Induced Modifications of P3HT: a Donor Material for Organic Photovoltaic Devices. Vacuum 2017, 135, 73-85.

(8) Heeg, J.; Kramer, C.; Wolter, M.; Michaelis, S.; Plieth, W.; Fischer, W. J. Polythiophene $\mathrm{O}_{3}$ Surface Reactions Studied by XPS. Appl. Surf. Sci. 2001, 180, 36-41.

(9) Wang, J.; Friedman, C. R.; Cabrera, W.; Tan, K.; Lee, Y.-J.; Chabal, Y. J.; Hsu, J. W. P. Effect of Metal/Bulk-Heterojunction Interfacial Properties on Organic Photovoltaic Device Performance. J. Mater. Chem. A 2014, 2, 15288-15293. 
(10) Cogal, S.; Ela, S. E.; Cogal, G. C.; Micusik, M.; Omastova, M.; Oksuz, A. U. PlasmaEnhanced Modification of Multiwalled Carbon Nanotube with Conducting Polymers for Dye Sensitized Solar Cells. Polym. Compos. 2018, 39, 668-674.

(11) Xu, Z.; Chen, L.-M.; Yang, G.; Huang, C.-H.; Hou, J.; Wu, Y.; Li, G.; Hsu, C.-S.; Yang, Y. Vertical Phase Separation in Poly(3-Hexylthiophene): Fullerene Derivative Blends and Its Advantage for Inverted Structure Solar Cells. Adv. Funct. Mater. 2009, 19, 1227-1234. 